\section{Logit Models for Estimating Lethal Temperatures in Apple}

\author{
Leena Lindén, Hannu Rita ${ }^{1}$, and Terhi Suojala ${ }^{2}$ \\ Department of Plant Production, P.O. Box 27, FIN-00014, University of \\ Helsinki, Finland
}

Additional index words. frost resistance, logistic models, $\mathrm{LT}_{50}$, Malus domestica

\begin{abstract}
Logit models were used to analyze freeze-survival data of apple (Malus domestica Borkh.). The effects of hardening and dehardening treatments and two treatment durations on lethal temperature were studied using two cultivars. The major benefits of logit models were 1) the form of the sampling variation in the qualitative response variable was taken into account, 2) the lethal temperatures could be estimated with confidence intervals, and 3) the effects of treatments could be interpreted and compared easily using odds ratios. The momentary frost resistance estimates for 'Antonovka' and 'Samo' were -46 and $-43 \mathrm{C}$, respectively. Dehardening at $14 \mathrm{C}$ raised the lethal temperature by 12 to $\mathbf{1 5 C}$, whereas hardening at $\mathbf{- 1 5 C}$ did not affect the frost resistance of either cultivar.
\end{abstract}

A numeric expression of the level of lowtemperature tolerance often is needed in temperature stress research. Resistance indices, such as the temperature at $50 \%$ lethality $\left(\mathrm{LT}_{50}\right)$ (Levitt, 1972), the lowest survival temperature (LST) (Quamme et al., 1972), or the temperature interval between $10 \%$ and $90 \%$ injury (Ketchie et al., 1972), are desirable in studying the acclimation-deacclimation process or the effects of environmental stimuli on the degree of frost resistance. However, in many cases, the resistance indices are estimated graphically from temperature curves (e.g., Haynes et al., 1992; Montano et al., 1987; Ritchie et al., 1985). The shortcomings of these graphic methods are that there is an inclination to subjective bias errors, only rough estimates are produced, and the degree of confidence associated with the resistance index cannot be estimated.

A number of numerical methods for computing the lethal temperature have been presented: Spearman-Kärber for estimating the $\mathrm{LT}_{50}$ of flower buds (Bittenbender and Howell, 1974), linear regression for estimating lethal temperatures in conifer seedlings (Burr et al., 1993), nonlinear regression models for estimating the $\mathrm{LT}_{50}$ from freeze-induced electrolyte leakage data (Zhu and Liu, 1987), and calculating the sE of impedance-estimated frost resistance index $\left(\mathrm{LT}_{-10 \Omega \mathrm{m}}\right)$ (Repo and Lappi, 1989). However, as a rule, visual assessment of frost injuries is qualitative and discrete.

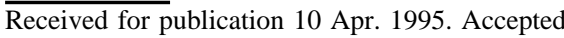
for publication 20 Oct. 1995. We acknowledge Aino-Maija Evers and Pertti Hari for their helpful comments on this paper. This work was supported by grants of Kemira and Wihuri Research foundations. The cost of publishing this paper was defrayed in part by the payment of page charges. Under postal regulations, this paper therefore must be hereby marked advertisement solely to indicate this fact.

${ }^{1}$ Current address: Dept. of Forest Resource Management/Statistics, P.O. Box 24, FIN-00014, Univ. of Helsinki, Finland.

${ }^{2}$ Current address: Agricultural Research Center, Institute of Horticulture, Toivonlinnantie 518, FIN21500 Piikkiö, Finland.
Since linear or nonlinear regression assumes continuous dependent variables, they are inappropriate in analyzing qualitative data (Aldrich and Nelson, 1984).

Logit models offer one alternative for analyzing freeze injury probabilities (Aldrich and Nelson, 1984; Collett, 1991). The simplest version of visual assessment (i.e., samples classified as living or dead) yields a binary response variable. The freeze-death probability $(\pi)$ is estimated as the proportion of dead samples. Then the risk of dying, or the odds of a freeze-death, is defined as the ratio of $\pi$ to the probability of its complement, $\pi /(1-\pi)$. In logit models, the odds of a freeze-death is subjected to logarithmic transformation: $\ln [\pi /$ $(1-\pi)]$. This transformation of $\pi$ is called the logit transformation, logit $(\pi)$.

The logit model for the dependence of $\pi$ on the freezing temperature, $\mathrm{T}$, is

$\operatorname{logit}[\pi(T)]=\ln \left(\frac{\pi(T)}{1-\pi(T)}\right)=\alpha+\beta \times T$,

which can easily be solved for $\pi(\mathrm{T})$, giving

$\pi(T)=\frac{e^{\alpha+\beta \times T}}{1+e^{\alpha+\beta \times T}}$.

Logit model parameter $\beta$ describes the magnitude of the effect of temperature $\mathrm{T}$ on freezedeath probability. The odds ratio $(\psi)$ is a relative measure of difference between two probabilities to be compared, $\pi(\mathrm{T}+1)$ and $\pi(\mathrm{T})$ :

$\psi=\frac{\pi(\mathrm{T}+1) /[1-\pi(\mathrm{T}+1)]}{\pi(\mathrm{T}) /[1-\pi(\mathrm{T})]}$.

By incorporating Eq. [1], $\psi$ depends only on the value of parameter $\beta$ : $\psi=\mathrm{e}^{\beta}$.

Hence, the odds for a freeze-death grows $\mathrm{e}^{\beta}$ -fold as the freezing temperature decreases by one unit (i.e., one degree Celsius). When the probabilities of $\pi(T+1)$ and $\pi(T)$ do not differ, the corresponding odds ratio is equal to unity and the coefficient $\beta$ is equal to zero. Ninetyfive percent confidence intervals for the odds ratio are formed by exponentiating the confidence intervals for the coefficient $\beta$ : $\mathrm{e}^{\hat{\beta} \pm 1.96 \times \mathrm{SE}}$, where SE is the SE of the estimate $\hat{\beta}$.

The right side of Eq. [1] can be extended to include numerical and categorical explanatory variables and interactions, and their effects are interpretable via odds ratios (Collett, 1991). Equation [2] provides freeze-death probabilities. Unlike ordinary regression models, logit models never predict inappropriate probabilities below zero or above unity.

Our objective was to evaluate logit models in determining the frost resistance of apple. In this study, frost resistance, defined as the ability to survive temperatures $\angle 0 \mathrm{C}$ (Sakai and Larcher, 1987) was measured by visual assessment of freeze-survival after artificial freezing tests.

\section{Materials and Methods}

Plant material. Sample twigs of two apple cultivars, 'Antonovka', an old, hardy cultivar of Russian origin, and 'Samo', a new Finnish cultivar (Säkö and Laurinen, 1986), were collected on 16 Mar. 1993 from established trees growing on rootstock A2 in the orchard of the Dept. of Plant Production, Univ. of Helsinki (lat. $60^{\circ} 10^{\prime} \mathrm{N}$, long. $25^{\circ} 00^{\prime} \mathrm{E}$ ). Moderately vigorous, 1-year-old twigs were sampled from the crowns of four trees per cultivar. The twigs were cut to $15-\mathrm{cm}$-long sections in a cold room (2C). They were randomly assigned to five sets of 24 samples per cultivar. Each set comprised three replications of eight samples from both cultivars. One set was immediately frozen (direct freezing) to measure the momentary frost resistance, whereas the four remaining sets were subjected to prefreezing treatments before freezing tests to determine the potential and minimum frost resistance (Larcher, 1985) of the trees in late winter. The four prefreezing treatments were 1) hardening at $-15 \mathrm{C}$ for 3 days or 2) 7 days, or 3 ) dehardening at $14 \mathrm{C}$ for 3 days or 4) 7 days. From each set, three cuttings per cultivar were retained at $2 \mathrm{C}$ during freezing tests and were used as controls.

Hardening was performed in a programmable, $1.6 \times 0.9-\mathrm{m}$, walk-in freezing chamber (Weiss 2600/45...5 Du-Pi, Weiss Umwelttechnik, Reiskirchen, Germany). Air temperature in the chamber was lowered at $5 \mathrm{C} / \mathrm{h}$ from 2 to $-15 \mathrm{C}$ and was kept constant $( \pm 1 \mathrm{C})$ for 3 or 7 days. Dehardening was performed by keeping the samples with their basal ends in tap water at $14 \pm 1 \mathrm{C}$ in a dark room. Samples were packed in double, 0.03-mm-thick polyethylene bags before freezing tests or hardening treatments. All treatments began within $12 \mathrm{~h}$ of sample collection.

Freezing tests. Samples were frozen in a freezing chamber (Weiss 2600) to seven test temperatures from -20 to $-50 \mathrm{C}$ with $5 \mathrm{C}$ intervals at $5 \mathrm{C} / \mathrm{h}$. In direct freezing, lowering the temperature started from $2 \mathrm{C}$, after hardening 
and dehardening treatments from -5 and $14 \mathrm{C}$, respectively. Air temperature was controlled by placing three thermocouples (type $\mathrm{K}$, Watlow Gordon, St. Louis) $(0.076 \mathrm{~mm}$ in diameter), attached to a datalogger (Datataker 500, Data Electronics, Boronia, Australia), between the sample bags. After being held at a selected test temperature for $30 \mathrm{~min}$, three cuttings of both cultivars were removed from the chamber, thawed at $2 \mathrm{C}$ for $24 \mathrm{~h}$, and placed in sand on a mist propagation bench for 14 to 21 days at 20 to $25 \mathrm{C}$.

Evaluation of freeze-survival and data analyses. After incubation, the uppermost 1$\mathrm{cm}$-long section and the basal, water-soaked, 2 to $3 \mathrm{~cm}$ of each sample were removed. The remaining internodal parts were sliced transversely and examined for survival under a dissecting microscope at $\times 6.5$ to $\times 20$ magnification. Judging the sample as living or dead was based on the degree of oxidative browning in xylem, the most susceptible of stem tissues, as described in Holubowicz et al. (1982).

The resulting data were analyzed using logit models with freezing temperatures, apple cultivars, prefreezing treatments, treatment durations, and their interactions as explanatory variables. Model goodness of fit was measured by the Hosmer-Lemeshow test (Hosmer and Lemeshow, 1989) because of the small number of observations per treatment; significance of the single parameters was checked by the Wald test (Hosmer and Lemeshow, 1989; also gives a discussion of the different tests feasible with logit models). The software used was BMDP logistic regression (LR) procedure (BMDP Statistical Software, 1990), with the maximum likelihood method for estimating parameters.

Estimation of $L T_{50}$. The $\mathrm{LT}_{50}$ is, by definition, the temperature $\mathrm{T}$ at which $\pi(\mathrm{T})$ equals 0.5 . By substituting $\pi(\mathrm{T})$ with 0.5 in Eq. [1], $\mathrm{LT}_{50}=-\alpha / \beta$ is obtained. The parameters for categorical explanatory variables (apple cultivars, prefreezing treatments, and treatment durations) were summed together to form an overall $\alpha$. Hence, different values of $\alpha$ and $\mathrm{LT}_{50}$ were obtained for each treatment combination. As the parameters ( $\alpha$ s and $\beta$ ) are estimated from experimental data, the $\mathrm{LT}_{50}$ also is subject to random variation. Based on SES and covariances of the parameters, confidence intervals for the $\mathrm{LT}_{50}$ s were determined (Collett, 1991).

\section{Results}

No interactions between the explanatory variables were statistically significant. Hence, only the main effects were included in the final model (Table 1). The Hosmer-Lemeshow statistic for the overall model was 8.15 with $\mathrm{df}=$ $8(P=0.42)$, indicating a satisfactory model fit.

The estimated parameter values and the corresponding odds ratios (Table 1) revealed that apple freeze-death probability (Fig. 1) increased when 1) the freezing temperature was lowered, 2) the cultivar was 'Antonovka' rather than 'Samo', or 3) a dehardening treatment was applied.
The momentary frost resistance estimates for 'Antonovka' and 'Samo' were -46 and $-43 \mathrm{C}$, respectively (Table 2). Hardening at $-15 \mathrm{C}$ had no detectable influence on the level of resistance (Table 1). Dehardening at $14 \mathrm{C}$ for 3 or 7 days raised the $\mathrm{LT}_{50}$ by 12 or $15 \mathrm{C}$, respectively, relative to direct freezing (Table 2). However, the difference between 3 and 7 days of dehardening treatments was not statistically significant (Table 1).

\section{Discussion}

In this study, we have used logit models, one of the regression procedures for qualitative dependent variables, for estimating apple frost resistance. In the field of agricultural sciences, logit models previously have been applied in economics, plant pathology, and entomology (e.g., Knopf and Schoney, 1993; Kortemaa et al., 1994; Legg et al., 1992). To our knowledge, there are no earlier reports on using logit models in temperature stress research.

A numeric frost resistance index, the $\mathrm{LT}_{50}$ with associated confidence intervals, was easily estimated with the aid of logit model parameters. Correspondingly, the critical temperature can be determined for any probability value desired. An additional benefit of logit models is that the effects of explanatory variables can be evaluated directly using model coefficients and odds ratios.

In our experiment, there were 210 observations to estimate the 20 potential parameters (main effects and interactions) of the logit model. Hence, we are facing the risk of an over-parameterized model. The proper relationship between sample size and the number of parameters is a problem with no obvious solution. In our study, the small number of observations per parameter is reflected in that the confidence intervals for model parameters and lethal temperatures grew wide. We might have done better by decreasing the number of pretreatments applied, thus the number of observations per parameter would have increased. The test temperature range and interval $(5 \mathrm{C}$ in

Table 1. Estimated parameter values of the logit model and the corresponding odds ratios with their $95 \%$ confidence intervals.

\begin{tabular}{|c|c|c|c|c|c|}
\hline \multirow[b]{2}{*}{ Parameter $^{2}$} & \multirow[b]{2}{*}{ Coefficient } & \multirow{2}{*}{$\begin{array}{l}P \text { value of } \\
\text { Wald test }{ }^{\mathrm{y}}\end{array}$} & \multirow{2}{*}{$\begin{array}{l}\text { Odds } \\
\text { ratio }\end{array}$} & \multicolumn{2}{|c|}{ 95\% Confidence-interval limits } \\
\hline & & & & Lower & Upper \\
\hline$\overline{\beta_{\text {temp }}}$ & 0.439 & $<0.01$ & 1.55 & 1.35 & 1.78 \\
\hline$\alpha_{\text {cult }}$ & 1.192 & 0.04 & 3.29 & 1.07 & 10.14 \\
\hline$\alpha_{\text {hard }}$ & 1.090 & 0.16 & 2.97 & 0.66 & 13.47 \\
\hline$\alpha_{\mathrm{ht}}$ & 0.690 & 0.43 & 1.99 & 0.36 & 11.16 \\
\hline$\alpha_{\text {deh }}$ & 5.883 & $<0.01$ & 357.81 & 35.41 & 3634.30 \\
\hline$\alpha_{\mathrm{dt}}$ & 1.468 & 0.10 & 4.35 & 0.76 & 24.65 \\
\hline$\alpha$ & -20.012 & --- & --- & --- & -- \\
\hline
\end{tabular}

${ }^{2}$ The model was parametrized as follows: $\beta_{\text {temp }}$ describes the effect of freezing temperature; $\alpha_{\text {cult }}$ compares 'Samo' to 'Antonovka'; $\alpha_{\text {hard }}$ and $\alpha_{\text {deh }}$ contrast the mean of the two hardening and dehardening treatments, respectively, to direct freezing; $\alpha_{\mathrm{ht}}$ and $\alpha_{\mathrm{dt}}$ compare the hardening and dehardening of 7 days to the corresponding 3 days of treatments. Positive value of a parameter always indicates higher injury probability in the group mentioned first in the comparison.

y Likelihood ratio tests agreed with these results.

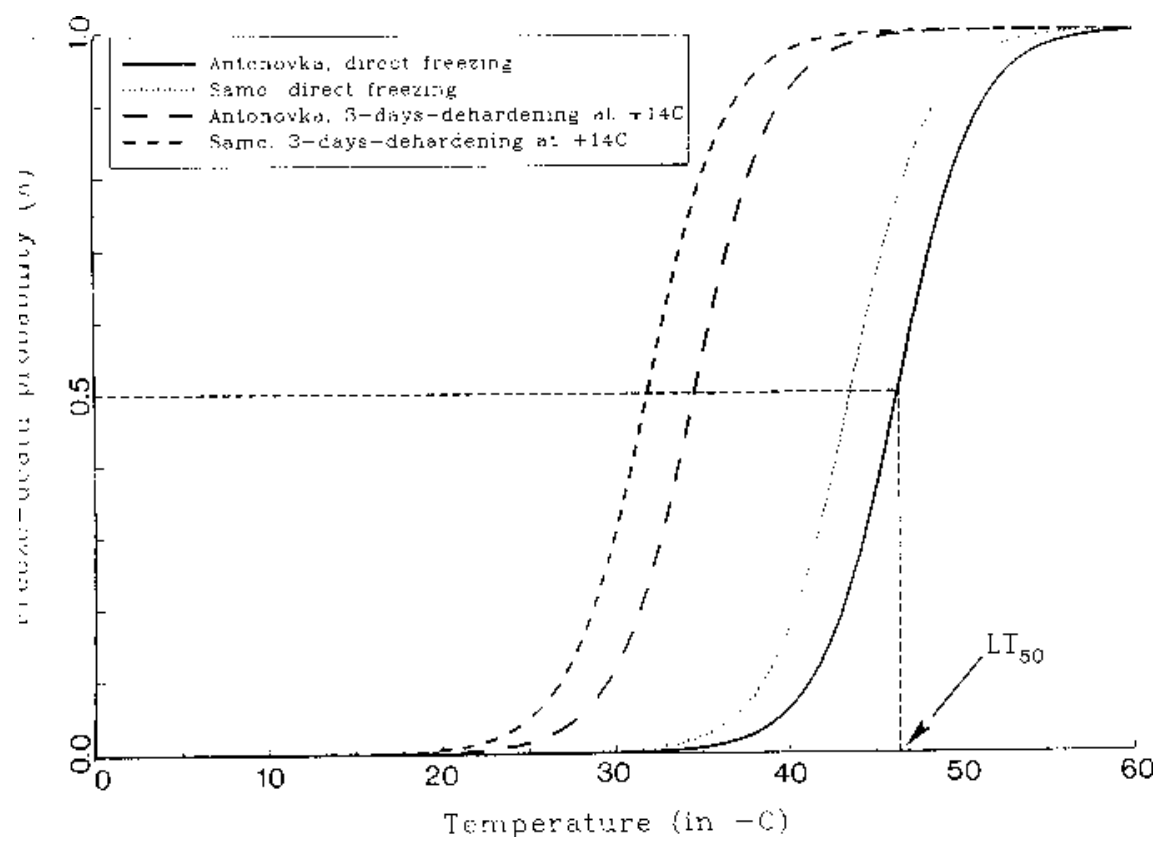

Fig. 1. Probabilities of freeze-death as a function of freezing temperature for two apple cultivars in direct freezing and after 3 days of dehardening treatment at $14 \mathrm{C}$. The straight line exemplifies determination of the temperature at $50 \%$ lethality $\left(\mathrm{LT}_{50}\right)$. The curves are of the same form because of no significant temperature $\times$ categorical explanatory variables interactions. 
our study) should be shortened to better capture the freeze-death process.

The newly bred Finnish apple 'Samo' was only a little less frost resistant than 'Antonovka', which is an extremely hardy cultivar (Emmert and Howlett, 1953). For apple species, there appears to be an ultimate limit of frost resistance between -40 and $-46 \mathrm{C}$ (Quamme, 1978). Lower temperatures break down the resistance mechanism of apple xylem, leading to lethal injury (Quamme et al., 1972). As the momentary frost resistance estimates for 'Samo' and 'Antonovka' were -43 and $-46 \mathrm{C}$, respectively, we conclude that both cultivars were close to the state of their maximum attainable hardiness at the time of sampling. Consequently, the hardening treatments applied did not increase the frost resistance of either cultivar.

The minimum resistance estimates, revealed by the dehardening treatments, were -31 to $-34 \mathrm{C}$ for 'Antonovka' and -28 to $-31 \mathrm{C}$

Table 2. Frost resistance [temperature at 50\% lethality $\left(\mathrm{LT}_{50}\right)$ in negative degrees Celsius] of two apple cultivars during direct freezing and after four pretreatments. Estimates by logit models.

\begin{tabular}{|c|c|c|c|}
\hline \multirow{3}{*}{$\begin{array}{l}\text { Procedure } \\
\text { and } \\
\text { cultivar }\end{array}$} & \multirow[b]{3}{*}{$\mathrm{LT}_{50}$} & \multirow{2}{*}{\multicolumn{2}{|c|}{$\begin{array}{c}95 \% \text { Confidence } \\
\text { interval of } \mathrm{LT}_{50} \\
\text { Band }\end{array}$}} \\
\hline & & & \\
\hline & & Lower & Upper \\
\hline \multicolumn{4}{|l|}{ Direct freezing } \\
\hline Antonovka & 46 & 42.5 & 48.8 \\
\hline Samo & 43 & 39.7 & 46.1 \\
\hline \multicolumn{4}{|c|}{ Hardening, 3 days } \\
\hline Antonovka & 44 & 40.5 & 47.1 \\
\hline Samo & 41 & 37.7 & 44.6 \\
\hline \multicolumn{4}{|c|}{ Hardening, 7 days } \\
\hline Antonovka & 42 & 39.1 & 45.6 \\
\hline Samo & 40 & 36.5 & 42.8 \\
\hline \multicolumn{4}{|c|}{ Dehardening, 3 days } \\
\hline Antonovka & 34 & 29.9 & 37.8 \\
\hline Samo & 31 & 27.7 & 34.5 \\
\hline \multicolumn{4}{|c|}{ Dehardening, 7 days } \\
\hline Antonovka & 31 & 27.4 & 33.6 \\
\hline Samo & 28 & 24.6 & 30.9 \\
\hline
\end{tabular}

${ }^{2}$ Direct freezing means the samples were freezetested immediately after collection; hardening was at $-15 \mathrm{C}$; dehardening was at $14 \mathrm{C}$. for 'Samo'. As the dehardening was performed by keeping the samples with their bases in water, the reduction in resistance might not be due to the deacclimating temperature only. An increase in water content in plant tissues apparently coincides with an abrupt loss of frost resistance (Sakai and Larcher, 1987).

Our results demonstrate that logit models provide a highly useful alternative for analysis of qualitative temperature-stress data and for estimating the lethal temperature. If freezing injuries are recorded using ordinal classification (i.e., several injury classes), the ordinal logit technique can be used.

\section{Literature Cited}

Aldrich, J.H. and F.D. Nelson. 1984. Linear probability, logit, and probit models. Sage Univ. Paper Ser. on Quantitative Applications in the Social Sciences, 45. Sage Publishing, Beverly Hills, Calif.

Bittenbender, H.C. and G.S. Howell, Jr. 1974. Adaptation of the Spearman-Kärber method of estimating the $\mathrm{T}_{50}$ of cold stressed flower buds. J. Amer. Soc. Hort. Sci. 99:187-189.

BMDP Statistical Software. 1990. BMDP statistical software manual. vol. 2. BMDP Statistical Software, Los Angeles.

Burr, K.E., S.J. Wallner, and R.W. Tinus. 1993. Heat tolerance, cold hardiness, and bud dormancy relationships in seedlings of selected conifers. J. Amer. Soc. Hort. Sci. 118:840-844.

Collett, D. 1991. Modelling binary data. Chapman and Hall, London.

Emmert, F.H. and F.S. Howlett. 1953. Electrolytic determinations of the resistance of fifty-five apple varieties to low temperatures. Proc. Amer. Soc. Hort. Sci. 62:311-318.

Haynes, C.L., O.M. Lindstrom, and M.A. Dirr. 1992. Cooling and warming effects on cold hardiness estimations of three woody ornamental taxa. HortScience 27:1308-1309.

Holubowicz, T., J.N. Cummins, and P.L. Forsline. 1982. Responses of Malus clones to programmed low-temperature stresses in late winter. J. Amer. Soc. Hort. Sci. 107:492-496.

Hosmer, D.W. and S. Lemeshow. 1989. Applied logistic regression. Wiley, New York.

Ketchie, D.O., C.H. Beeman, and A.L. Ballard. 1972. Relationship of electrolytic conductance to cold injury and acclimation in fruit trees. $\mathrm{J}$. Amer. Soc. Hort. Sci. 97:403-406.

Knopf, E. and R. Schoney. 1993. An evaluation of farm financial benchmarks and loan success/ failure: The case of the Agricultural Credit Corporation of Saskatchewan. Can. J. Agr. Econ. 41:61-69.

Kortemaa, H., H. Rita, K. Haahtela, and A Smolander. 1994. Root-colonizing ability of antagonistic Streptomyces griseovirdis. Plant \& Soil 163:77-83.

Larcher, W.J. 1985. Frostresistenz, p. 177-260. In: B. Rademacher and H. Richter (eds.). Handbuch der Pflanzenkrankheiten 1. Band, 7. Auflage, 5. Lieferung. Paul Parey, Berlin.

Legg, D.E., G.L. Hein, R.M. Nowierski, M.G. Feng, F.B. Peairs, M. Karner, and G.W. Cuperus. 1992. Binomial regression models for spring and summer infestations of the Russian wheat aphid (Homoptera: Aphididae) in the southern and western plains states and Rocky Mountain region of the United States. J. Econ. Entomol. 85:1779-1790.

Levitt, J. 1972. Responses of plants to environmental stresses. Academic, New York.

Montano, J. M., M. Rebhuhn, K. Hummer, and H.B. Lagerstedt. 1987. Differential thermal analysis for large-scale evaluation of pear cold hardiness. HortScience 22:1335-1336.

Quamme, H.A. 1978. Breeding and selecting temperate fruit crops for cold hardiness, p. 313-332. In: P.H. Li and A. Sakai (eds.). Plant cold hardiness and freezing stress. Academic, New York.

Quamme, H.A., C. Stushnoff, and C.J. Weiser. 1972. The relationship of exotherms to cold injury in apple stem tissue. J. Amer. Soc. Hort. Sci. 97:608-613.

Repo, T. and J. Lappi. 1989. Estimation of standard error of impedance-estimated frost resistance. Scand. J. For. Res. 4:67-74.

Ritchie, G.A., J.R. Roden, and N. Kleyn. 1985 Physiological quality of lodgepole pine and interior spruce seedlings: Effects of lift date and duration of freezer storage. Can. J. For. Res. 15:636-645.

Sakai, A. and W. Larcher. 1987. Frost survival of plants. Springer-Verlag, Berlin.

Säkö, J. and E. Laurinen. 1986. Apple variety Samo. Ann. Agr. Fenniae 25:1-3.

Zhu, G.H. and Z.Q. Liu. 1987. Determination of median lethal temperature using logistic function, p. 291-298. In: P.H. Li (ed.). Plant cold hardiness. Alan R. Liss, New York. 